\title{
Feature-Selective Attention in Healthy Old Age: A Selective Decline in Selective Attention?
}

\author{
Cliodhna Quigley ${ }^{1}$ and Matthias M. Müller ${ }^{2}$ \\ ${ }^{1}$ Cognitive Neuroscience Laboratory, German Primate Center, D-37077 Goettingen, Germany, and ${ }^{2}$ Institute of Psychology, University of Leipzig, D-04103 \\ Leipzig, Germany
}

Deficient selection against irrelevant information has been proposed to underlie age-related cognitive decline. We recently reported evidence for maintained early sensory selection when older and younger adults used spatial selective attention to perform a challenging task. Here we explored age-related differences when spatial selection is not possible and feature-selective attention must be deployed. We additionally compared the integrity of feedforward processing by exploiting the well established phenomenon of suppression of visual cortical responses attributable to interstimulus competition. Electroencephalogram was measured while older and younger human adults responded to brief occurrences of coherent motion in an attended stimulus composed of randomly moving, orientation-defined, flickering bars. Attention was directed to horizontal or vertical bars by a pretrial cue, after which two orthogonally oriented, overlapping stimuli or a single stimulus were presented. Horizontal and vertical bars flickered at different frequencies and thereby elicited separable steady-state visual-evoked potentials, which were used to examine the effect of feature-based selection and the competitive influence of a second stimulus on ongoing visual processing. Age differences were found in feature-selective attentional modulation of visual responses: older adults did not show consistent modulation of magnitude or phase. In contrast, the suppressive effect of a second stimulus was robust and comparable in magnitude across age groups, suggesting that bottom-up processing of the current stimuli is essentially unchanged in healthy old age. Thus, it seems that visual processing per se is unchanged, but top-down attentional control is compromised in older adults when space cannot be used to guide selection.

Key words: feature-based attention; healthy aging; human EEG; steady state visual evoked potentials

\section{Introduction}

An influential theory of cognitive aging claims that a failure to inhibit irrelevant information at different processing stages underlies age-related cognitive decline (Hasher and Zacks, 1988; for review, see Lustig et al., 2007). Attention is a well studied cognitive mechanism involving flexible selection of relevant sensory information. Because selective attention comprises prioritization of relevant and deprioritization of irrelevant stimuli, its experimental paradigms provide an established means of testing sensory selection in older adults. When task relevance is spatially defined, attentional modulation of early visual responses seems unchanged in healthy old age (Quigley et al., 2012). Selection can also be guided by visual features, and an exploratory study requiring color-based selection among overlapping random dot

Received June 27, 2013; revised Nov. 17, 2013; accepted Nov. 24, 2013.

Author contributions: C.Q. and M.M.M. designed research; C.Q. performed research; C.Q. analyzed data; C.Q. and M.M.M. wrote the paper.

This research was supported by the Deutsche Forschungsgemeinschaft graduate program "Function of Attention in Cognition." The experiment used Cogent Graphics, developed by John Romaya at the Laboratory of Neurobiology, Wellcome Department of Imaging Neuroscience. Thanks to Matthias Ihrke for his blink-correction EEGLAB plug-in, Felix Dreyer and Marina Winkler for conducting the behavioral control, and Durk Talsma and an anonymous reviewer for helpful feedback.

This article is freely available online through the J Neurosci Author Open Choice option.

Correspondence should be addressed to Matthias M. Müller at the above address. E-mail: m.mueller@uni-leipzig.de.

DOI:10.1523/JNEUROSCI.2718-13.2014

Copyright $\odot 2014$ the authors $\quad 0270-6474 / 14 / 342471-06 \$ 15.00 / 0$ patterns revealed performance deficits and lack of attentional modulation in older adults (Quigley et al., 2010). Here we address two questions: (1) does this feature-selective deficit generalize beyond color; and (2) are age differences attributable to altered bottom-up visual processing?

To investigate the first question, we tested whether older and younger adults differed when orientation is the task-relevant feature. Participants selectively attended to one of two overlapping, randomly moving stimuli composed of orientation-defined items (horizontal or vertical bars) and responded to coherent motion in the cued stimulus only. Behavioral performance and the effect of attention on an index of early visual processing, the steady-state visual evoked potential (SSVEP), were analyzed to evaluate feature-selective attention. Similar task manipulations are known to robustly modulate SSVEP amplitude in younger adults (Müller et al., 2006).

To answer the second question, we included trials with only one orientation-defined stimulus. Contrasting the response to a stimulus presented alone versus with a concurrent, second stimulus quantifies the bottom-up-driven mutual suppression exerted by two stimuli in competition for cortical representation (Desimone and Duncan, 1995). The magnitude of the SSVEP response to a stimulus decreases when a second stimulus is presented close to (Keitel et al., 2013) or overlapping (Busse et al., 2009 ) it. Because this occurs for attended or unattended stimuli (Keitel et al., 2013), this amplitude reduction reflects a purely 
bottom-up, competitive effect. Orientation selectivity is a defining property of neurons in early visual cortex (Hubel and Wiesel, 1962). The suppressive effect of orthogonally oriented stimuli has accordingly been found in primary visual cortex (V1) (Busse et al., 2009), and nonspatial orientation-selective attention effects have also been localized there (Liu et al., 2007). Thus, this measure of between-stimulus suppression is used here to investigate the integrity of bottom-up orientation processing in older and younger adults to provide insight into possible causes of agerelated decline in feature-selective attention.

\section{Materials and Methods}

Participants. Participants gave informed consent, and the experiment conformed to local and national ethical guidelines. Subjects were recruited via advertisement and laboratory databases. Requirements were mini-mental state examination (Folstein et al., 1975) $\geq 27$, corrected binocular decimal visual acuity $\geq 0.5$, and less than two orders of magnitude difference between corrected monocular acuities (one younger, one older participant excluded). Two older participants were rejected after low training performance. Twenty younger (aged 20-31 years, mean of 25 years; 10 females; 15 right-handed) and 20 older (aged 61-74 years, mean of 67 years; 10 females; 15 right-handed) adults completed the experiment. Years of education did not differ (two-sample $t$ test, $p=0.284$ ). Computerbased vision tests (Bach, 1996) revealed that the older adults' corrected acuity was lower $\left(p=1.552 \times 10^{-4}\right)$ and contrast thresholds higher $(p=0.002)$, in line with normal changes (Owsley, 2011).

Experimental procedure. Subjects sat $\sim 80 \mathrm{~cm}$ from a CRT monitor $(120 \mathrm{~Hz}, 19$ inches, $800 \times 600$ resolution) in a dimly lit, electrically shielded chamber. Self-paced screen-based instructions included repeatable examples of targets. Training blocks contained 10 trials; events (targets/distractors) were more frequent ( $80 \%$ of trials) to facilitate training. Training continued until performance stabilized. Speed and accuracy were equally emphasized. Participants were instructed to maintain fixation and avoid blinks during trials. Electrooculogram was monitored for compliance, and feedback was provided.

Trials began with a centrally presented cue $(1.5 \mathrm{~s})$ depicting the taskrelevant orientation (horizontal/vertical; Fig. 1), followed by fixation $(0.5$ s), then one or two superimposed stimuli composed of flickering bars lasting for $4.167 \mathrm{~s}$. Horizontal bars flickered at $15 \mathrm{~Hz}$ (four frames on, four off) and vertical at $\sim 17 \mathrm{~Hz}$ (four frames on, three off). Each stimulus contained 75 bars $\left(20 \times 4\right.$ pixels, $0.6^{\circ} \times 0.1^{\circ} ; 3.45 \mathrm{~cd} / \mathrm{m}^{2}$ on $64.8 \mathrm{~cd} / \mathrm{m}^{2}$ background) in a central, circular, invisible aperture (200 pixel radius, $\left.6.3^{\circ}\right)$. Bars moved 1 pixel/frame in random oblique directions $\left(5.36^{\circ} / \mathrm{s}\right)$ with Brownian motion (Pilly and Seitz, 2009) and appeared to jitter. Bars that exited the aperture were redrawn in the diametrically opposite position. Subjects responded by button press to coherent oblique movements (randomly changing $40 \%$ of bars, $0.5 \mathrm{~s}$ ) in the attended stimulus. Coherent motion in the unattended stimulus constituted a distractor; responses counted as false alarms. Events had unpredictable onsets 1.5$3.5 \mathrm{~s}$ after stimulus onset, with $>1 \mathrm{~s}$ between events. This constituted a detection task when a single oriented stimulus was displayed and a selective attention task when two superimposed, orthogonally oriented stimuli were present, yielding four conditions ("Detect Horizontal," "Detect Vertical," "Select Horizontal," and "Select Vertical"). Detect conditions each had 70 trials: 10 contained one and 10 contained two targets (distractor events not possible). Select conditions each had 90 trials: 20 contained one and 20 two events (target or distractor equally likely). Fifty trials of each condition contained no events. Condition order was randomized trial by trial, and trials were grouped into eight blocks of $\sim 5$ min. Performance-related feedback was given between blocks. Response hand was counterbalanced by varying initial hand and changing halfway.

EEG recording and preprocessing. EEG, electrooculogram, and earlobe references were recorded with a 64-electrode system $(256 \mathrm{~Hz}$; ActiveTwo; BioSemi). EEGLAB (Delorme and Makeig, 2004) and MATLAB (MathWorks) were used for preprocessing and analysis. Data were epoched (0-3 s with respect to stimulus onset), and blinks and eye movements were automatically identified. Epochs containing eye movements were removed. For subjects with $>40$ remaining trials containing blinks (two

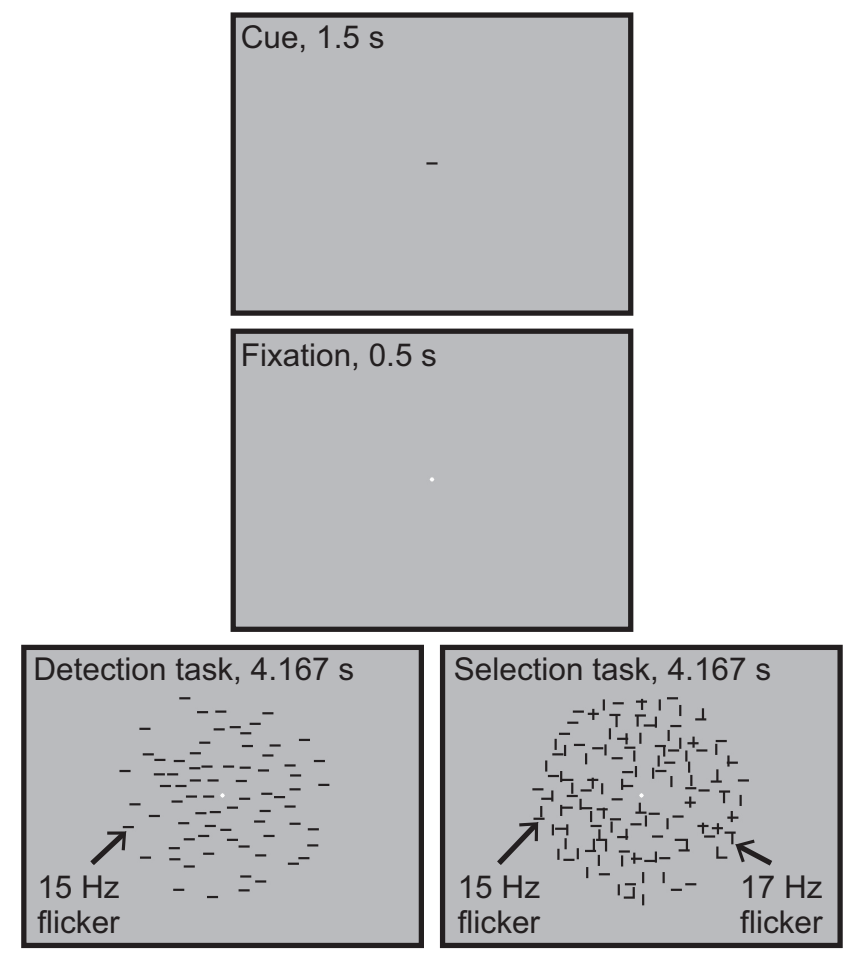

Figure 1. Task design. Trials began with a cue (1.5 s) indicating the task-relevant orientation. After a brief delay $(0.5 \mathrm{~s})$, one (detection trials, bottom left) or two (selective attention trials, bottom right) stimuli composed of randomly moving oriented bars were displayed for $4.167 \mathrm{~s}$. Subjects responded to brief events $(0.5 \mathrm{~s})$ of coherent, oblique motion in the relevant stimulus. Zero to two events (target and/or distractor) were possible from 1.5-3.5 s after stimulus onset.

younger, two older adults), linear regression correction was performed (Gratton et al., 1983). Artifacts were rejected/corrected using the SCADS (statistical control of artifacts in dense array studies) algorithm (Junghöfer et al., 2000), and data were transformed to average reference. Condition means were calculated for each subject from trials containing no coherent motion in the interval $0-2.5 \mathrm{~s} ; \geq 40$ trials contributed to each subject's means.

Complex-valued SSVEPs were calculated by Fourier transform of condition means for each subject, condition, and channel separately within a $2 \mathrm{~s}$ window, with the initial $0.5 \mathrm{~s}$ excluded to avoid contamination by onset VEP. Steady-state amplitudes for each stimulation frequency (15 and $17.14 \mathrm{~Hz}$ ), averaged over conditions containing that stimulation frequency, were used to select a subset of channels for additional analysis. Variance within age groups (Fig. 2A) motivated selection of three electrodes with maximum amplitudes individually for each subject and frequency (Andersen et al., 2011). Grand-averaged SSVEP spectra indicate that both stimuli elicited a robust SSVEP in both age groups (Fig. 2B). Although no spatial constraints were used, all selected electrodes were located at parietal and occipital sites (P, PO, and $\mathrm{O}$ in the 10-10 system). To avoid undesirable effects when averaging complex-valued data, the average over electrodes was taken as the last within-subject step before statistical analysis.

Statistical analyses. Responses 300-1300 ms after target/distractor onset were classified as hits/false alarms, respectively. Accuracy (number of hits plus correct rejections divided by number of events in selective attention conditions; number of hits divided by number of targets in detection conditions) and median reaction time (RT) were calculated for each subject and condition. Mixed-model ANOVAs with betweensubject factor age (young/old) and within-subject factors orientation (attend vertical/horizontal) and task (detect/select) were applied when appropriate.

Attentional modulation of SSVEP amplitude was quantified by comparing the response to each stimulus when it was attended versus unat- 
A

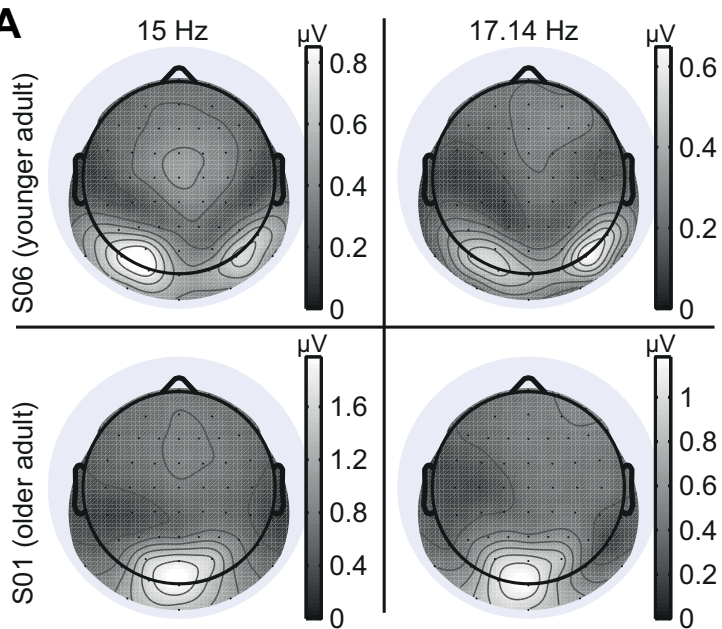

B

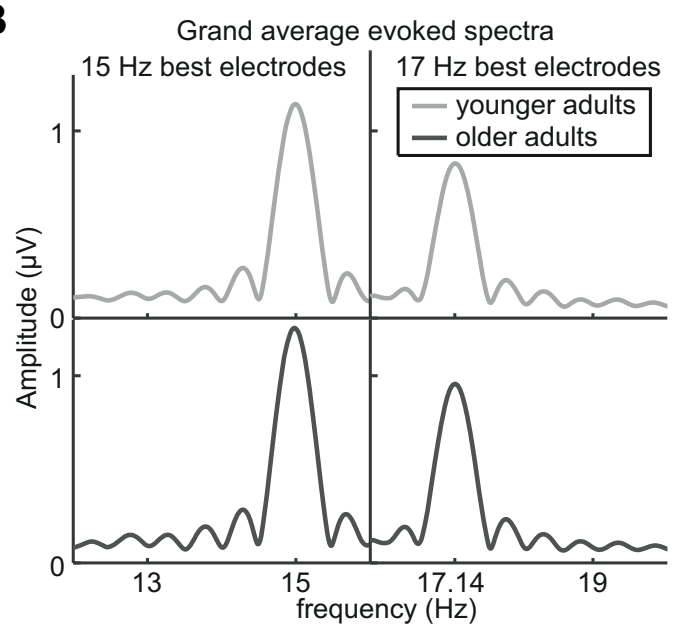

Figure 2. SSVEP amplitude. A, Isocontour voltage maps of SSVEP amplitudes for two exemplary subjects. The illustrated between-subject variance motivated the subject-specific choice of the three highest-amplitude electrodes for additional analysis. Note the different scales. $\boldsymbol{B}$, Group-averaged amplitude spectra for a subset of frequencies surrounding horizontal $(15 \mathrm{~Hz})$ and vertical $(\sim 17 \mathrm{~Hz})$ stimulus flicker.

tended in the selection task. Typically, modulation is quantified using a stimulus-specific attention index (AI), calculated as the difference in SSVEP amplitude when the stimulus was attended and unattended divided by the sum. AI distributions were subjected to a mixed-model ANOVA, and the distributions of each age group were tested against zero in post hoc tests.

Luminance-driven flicker also affects SSVEP phase (Di Russo et al., 2001), and attention modulates phases of entrained oscillations (Lakatos et al., 2008). Thus, we additionally applied the $T^{2}{ }_{\text {circ }}$ statistic (Victor and Mast, 1991), which treats complex-valued Fourier components as vectors, avoiding decomposition into amplitude and phase. The coherently averaged complex-valued SSVEP and its circular confidence region can be compared between groups (two-sample test) or to zero (single-sample test). If a sample contains vectors with similar phases, the confidence region surrounding the vector mean may significantly differ from zero even for small-magnitude vectors. Conversely, if a sample has uniformly distributed phases, the confidence region will likely include zero, regardless of the magnitudes of the vectors. A major limitation is that the SSVEP elicited by stimuli with distinct flicker frequencies cannot be averaged; disparate phase relations between stimulus and response could cancel or falsely inflate effects of interest. This precluded any test of interactions between orientation and age group. To discount any influence of SSVEP magnitude differences between subjects and/or groups, a complexvalued AI (complex-valued difference divided by summed magnitude of attended and unattended responses) was used.

To quantify suppressive effects of a second stimulus on the SSVEP elicited by the task-relevant stimulus, we created a suppression index (SI; amplitude in detection condition minus the selection condition in which that stimulus was attended, divided by the sum) and applied a mixedmodel ANOVA. We additionally used $T^{2}$ circ to test a complex-valued version of the SI for between-group differences and within-group differences versus zero. All $p$ values are uncorrected for multiple comparisons.

\section{Results}

\section{Behavioral}

To exclude effects of visual decline on older adults' performance, we correlated contrast sensitivity with hit rates and RT in detection conditions. Coefficients did not differ significantly from zero (Spearman's $\rho$ : horizontal hit rate $=0.261$, vertical hit rate $=0.341$; horizontal $\mathrm{RT}=-0.205$, vertical $\mathrm{RT}=0.163$; all $p$ values $>0.1$ ).

Older adults were overall slower to respond to targets (Fig. $3 A$; age, $\left.F_{(1,38)}=63.634, p=1.221 \times 10^{-9}\right)$. Both groups were faster when attending to vertical bars (orientation, $F_{(1,38)}=25.276$, $p=1.218 \times 10^{-5}$ ) and when only one stimulus was present (task, $\left.F_{(1,38)}=90.164, p=1.411 \times 10^{-11}\right)$. All interactions were non-
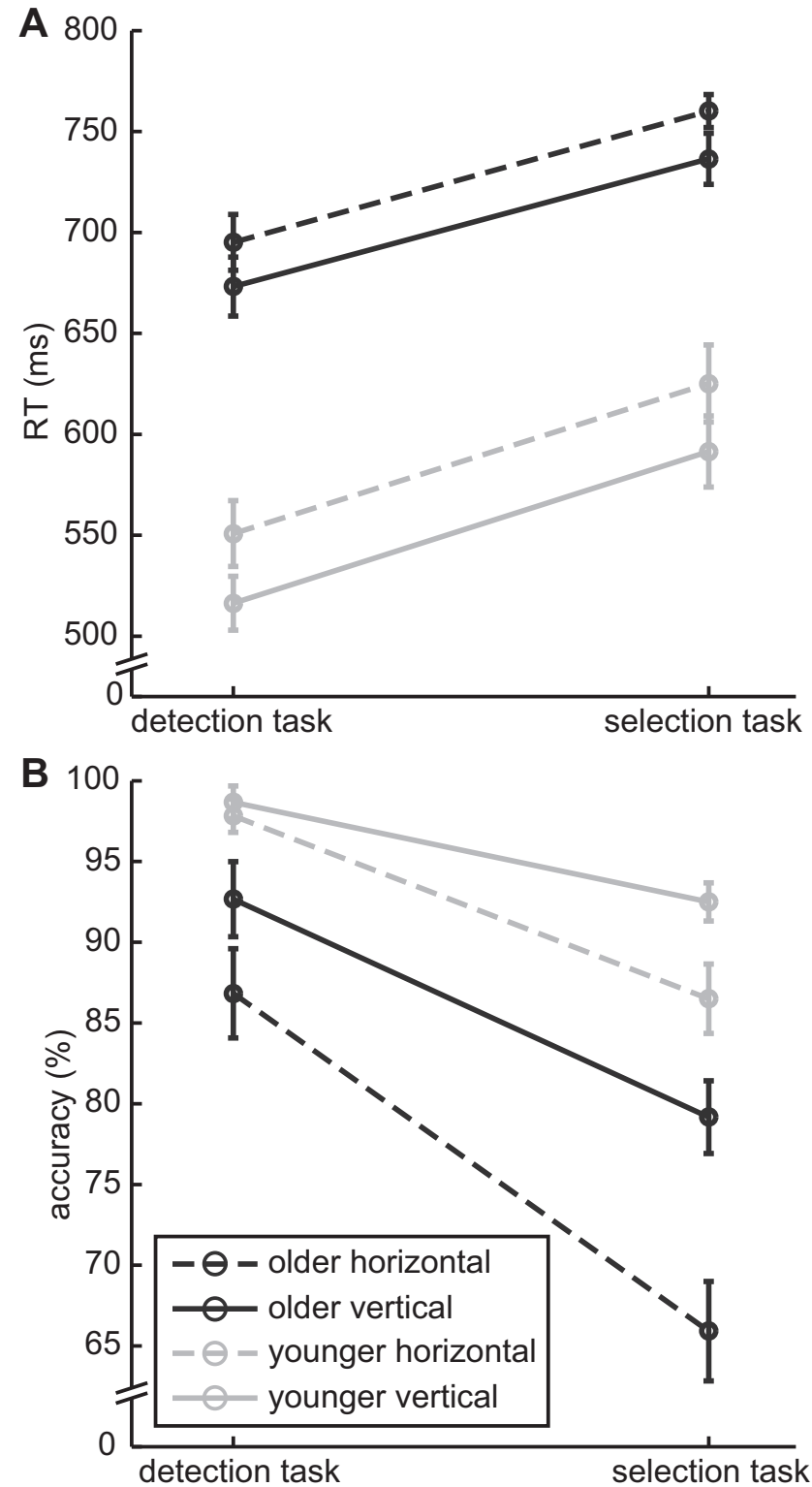

Figure 3. Behavioral results. Median RT $(\boldsymbol{A})$ and mean accuracy $(\boldsymbol{B})$ are shown for each age group, task, and attended stimulus. Error bars depict SEM. 
A
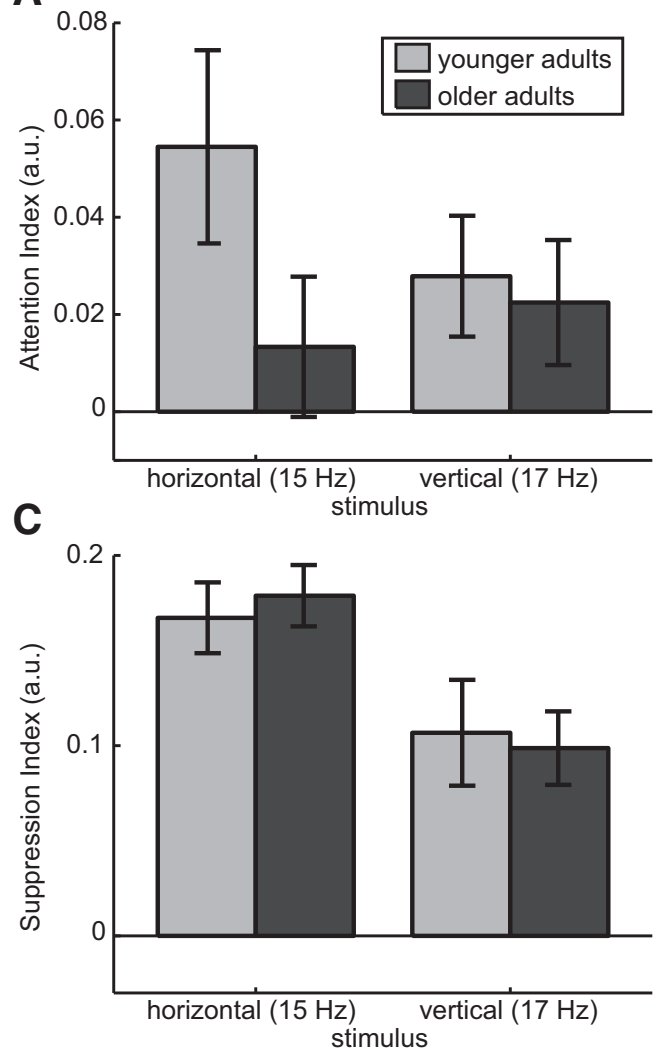

B

Complex-valued Attention Index

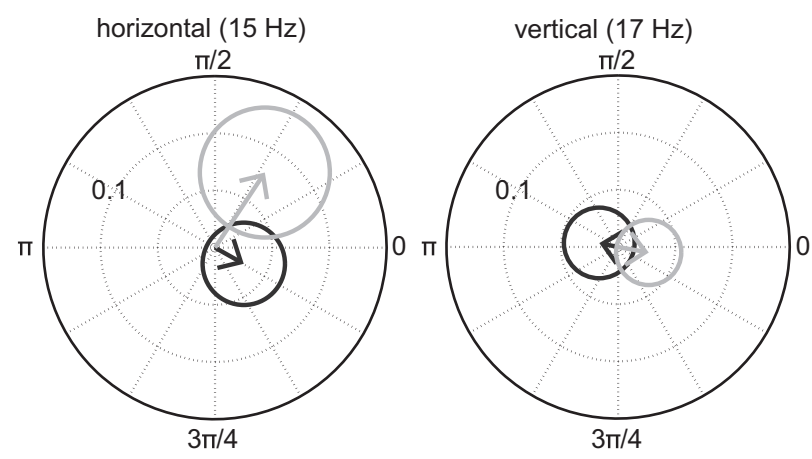

D Complex-valued Suppression Index

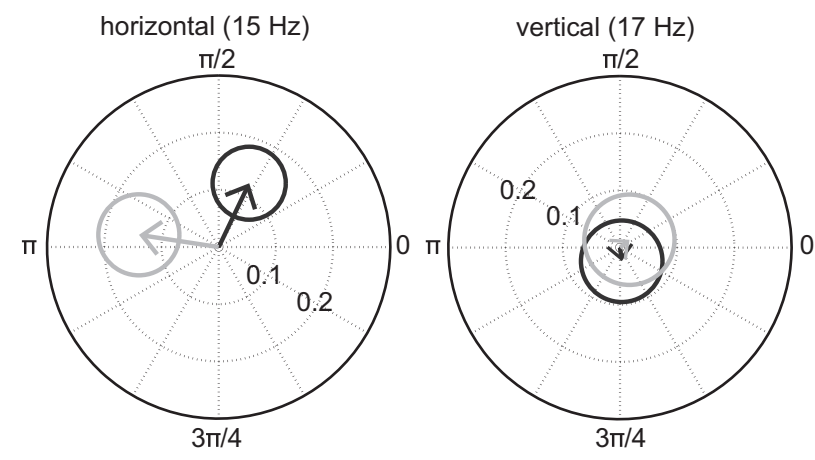

Figure 4. SSVEP modulations. $A$, Attentional modulation. Group mean of Al for each stimulus. Values above 0 indicate that SSVEP amplitude was larger in response to a stimulus when it was attended compared with unattended. Error bars show SEM. B, Group-averaged complex-valued Al for each stimulus. Arrows depict vector means and are surrounded by $95 \%$ confidence regions. Confidence regions that do not overlap the origin indicate that attention significantly modulated the SSVEP in response to that stimulus. C, Bottom-up-driven suppression. Group mean of SI, as in $A$. Values above 0 indicate that SSVEP amplitude was larger in response to a stimulus presented alone compared with simultaneously presented with the orthogonal orientation. $\boldsymbol{D}$, Group-averaged complex-valued SI, as in $\boldsymbol{B}$.

significant (largest $F=1.002$, all $p$ values $>0.3$ ). Younger adults were more accurate on average (Fig. $3 B$ ). However, a ceiling effect in detection conditions (15 younger subjects had 100\% accuracy for horizontal, 17 for vertical; five older adults had $100 \%$ for horizontal, 11 for vertical) prevented meaningful application of the factors used for RT analysis.

The age-independent effect of orientation on performance was unexpected. Because orientation was confounded with flicker frequency, we ran a behavioral control experiment (selective attention task only) with an additional group of 16 younger adults (20-30 years old, mean of 23 years; 11 females) in which flicker frequency was counterbalanced across orientations and randomized across trials. A two-factor (orientation and frequency) repeated-measures ANOVA revealed a clear effect of frequency for $\operatorname{RT}\left(F_{(1,15)}=25.143, p=1.541 \times 10^{-4}\right)$ and accu$\operatorname{racy}\left(F_{(1,15)}=41.973, p=1.041 \times 10^{-5}\right)$, replicating the current behavioral result. However, orientation did not affect either measure $(F$ values $<0.5$, $p$ values $>0.5)$, and orientation $\times$ frequency interactions were nonsignificant $(p$ values $>0.3$ ). This suggests that the task is easier for faster-flickering stimuli.

\section{Attentional enhancement}

The standard measure used to quantify attentional modulation of SSVEP ignores phase and looks only at amplitude (AI; Fig. 4A). Here, it may not have been sensitive enough to detect the expected age effect or a possible interaction in the omnibus test (age, $F_{(1,38)}=1.914, p=0.175$; orientation, $F_{(1,38)}=0.429$, $p=0.516$; age $\times$ orientation, $\left.F_{(1,38)}=1.789, p=0.189\right)$. Post hoc tests of AI distributions versus zero were significant only for the younger group (horizontal, $t_{(19)}=2.743, p=0.013$; vertical, $\left.t_{(19)}=2.243, p=0.037\right)$, although older adults showed a trend to significance for vertical stimuli (horizontal, $t_{(19)}=0.925$, $p=0.367$; vertical, $\left.t_{(19)}=1.747, p=0.097\right)$.

A more powerful test is provided by the $T_{\text {circ }}^{2}$ test, which includes SSVEP amplitude and phase. Older and younger adults significantly differed in average attentional modulation for each stimulus (Fig. $4 B$; horizontal, $T^{2}{ }_{\text {circ(2,76) }}=0.481, p=0.011$; vertical, $\left.T_{\text {circ }(2,76)}^{2}=0.356, p=0.033\right)$. Younger adults' complexvalued AI significantly differed from zero for horizontal stimuli $\left(T_{\text {circ }(2,38)}^{2}=0.312, p=0.005\right)$, with an average decrease in phase corresponding to $10.454 \mathrm{~ms}$, but showed only a trend for vertical $\left(T_{\text {circ }(2,38)}^{2}=0.149, p=0.063\right)$ and no change in phase on average. In contrast, the older group's complex-valued AI did not differ from zero for either stimulus (horizontal, $T_{\text {circ }(2,38)}^{2}=$ $0.104, p=0.139$; vertical, $\left.T^{2}{ }_{\operatorname{circ}(2,38)}=0.048, p=0.394\right)$.

\section{Mutual suppression}

The SI is clearly greater than zero for both groups (Fig. 4C), indicating that the SSVEP amplitude elicited by the task-relevant stimulus was robustly modulated by the presence of a second, orthogonal stimulus. The magnitude of this suppressive effect was larger for vertical bars (main effect of orientation, $F_{(1,38)}=$ $\left.19.020, p=0.954 \times 10^{-5}\right)$ but no main effect of age $\left(F_{(1,38)}=\right.$ $0.005, p=0.943)$ or interaction $\left(F_{(1,38)}=0.374, p=0.545\right)$ was 
found. Age groups significantly differed in complex-valued SI for horizontal stimuli-driven clearly by differing phase effects (Fig. $4 D)$ - but not for vertical stimuli (horizontal, $T^{2}{ }_{\text {circ }(2,76)}=1.613$, $p=1.450 \times 10^{-6}$; vertical, $\left.T_{\text {circ(2,76) }}^{2}=0.045, p=0.638\right)$. Significant modulation was found within both groups for horizontal stimuli only (younger, $T^{2}{ }_{\text {circ(2,38) }}=0.642, p=5.483 \times 10^{-5}$; older, $T^{2}{ }_{\operatorname{circ}(2,38)}=0.606, p=8.449 \times 10^{-5}$; vertical, both $p$ values $>0.6$ ). Given the suppressive effect on amplitude (SI; Fig. $4 C$ ), this suggests that a consistent effect on phase occurred only for horizontal stimuli.

\section{Discussion}

We compared behavioral performance and cortical effects of feature-based attention in younger and older adults in a task requiring selection by orientation. Additionally, an interleaved detection task with the same stimuli allowed us to assess the integrity of bottom-up orientation processing. Although the stimulus parameters used here should be above older adults' thresholds (Snowden and Kavanagh, 2006), we ruled out a relationship between measured contrast sensitivity and detection performance, which suggests that optical differences did not contribute to our results (cf. Allen et al., 2010). Older adults were overall slower to respond to targets, but we found no differential effect of task (detect/select), suggesting that this age difference reflects general age-related slowing rather than a deficit specific to the attentional task. This is not unexpected, because a simple stimulus-response mapping was used and task-related effects of age on RT generally arise at the later processing stage of response selection (Yordanova et al., 2004). Unfortunately, a ceiling effect in accuracy precluded analysis of a differential effect of age on performance in the detection and selective attention versions of the task.

Behavioral responses were faster and more accurate for each age group when attending to vertical stimuli. A behavioral control experiment suggests that this behavioral advantage is attributable to the higher saliency of the faster-flickering stimulus. Differences were also seen in the SSVEP results: attentional effects were larger in younger adults for horizontal stimuli (Fig. 4A). This is in line with previous results regarding stimulus saliency: faster behavioral responses and larger effects of attention on SSVEP amplitude were found for lower contrast stimuli (Andersen et al., 2012). Interestingly, attentional effects on SSVEP phase were more consistent for horizontal stimuli than vertical stimuli in our younger group (Fig. $4 B$ ), whereas both age groups showed larger cross-stimulus suppression (Fig. 4C) and a more consistent phase effect (Fig. 4D). To our knowledge, such effects of stimulus saliency on attentional modulation of SSVEP phase and crossstimulus suppression have not yet been reported and are worthy of additional investigation.

The effect of the attentional manipulation on the SSVEP is a direct measure of the effect of feature selection on ongoing visual processing. The magnitude of attentional effects reported here was small for younger adults compared with those found in experiments using the feature color (for a similar pattern of results, see Andersen et al., 2008). Orientation-selective effects are expected to arise in V1, in which attentional modulation has been proposed to be weakest (Maunsell and Cook, 2002). In comparison, the SSVEP evoked by colored stimuli has been localized to broad sources, including extrastriate visual areas (Müller et al., 2006; Andersen et al., 2009), in which attentional effects are believed to be larger (Buffalo et al., 2010). The significant modulatory effect of attention we found in younger adults' complexvalued SSVEP and lack of a robust attention effect in older adults, combined with the difference between age groups (Fig. 4B), suggest that feature-selective attention did not exert a reliable topdown influence on sensory processing in older participants. Thus, we extend our previous finding of age-related change in feature-selective attention guided by stimulus color (Quigley et al., 2010) to a second feature, orientation. This is in line with previous reports of age differences in tasks requiring nonspatial selection (Talsma et al., 2006; Schmitz et al., 2010).

Could this decline in feature-selective attention be a consequence of impaired bottom-up processing? Existing evidence is mixed. Electrophysiological studies in anesthetized animals have revealed dramatic age-related declines in neuronal orientation selectivity in V1 (Schmolesky et al., 2000). Broadened feature tuning constitutes a change in bottom-up processing that could impair mediation of top-down attentional effects. In contrast, human psychophysical studies have failed to find age differences in orientation selectivity (Govenlock et al., 2009) and orientation tuning of collinear facilitation effects (Chan et al., 2012). This suggests that bottom-up visual processing is maintained in healthy old age. Our results agree with the latter findings. First, age had no effect on the strength of suppression exerted by a second stimulus on the SSVEP elicited by the task-relevant stimulus (SI; Fig. 4C). Second, although our stimuli contained the same number of "on" frames per flicker cycle, it was unavoidable that the higher frequency was present for comparatively more frames when the signal was integrated over time. Both age groups showed the same facilitation in performance for the slightly higher flicker frequency (Fig. 3), providing additional evidence that bottom-up processing of the current stimuli is unaffected by age. The only difference in this respect found between age groups was a larger average phase effect for the younger group in the complex-valued SI for horizontal stimuli, which should be qualified by the lack of an age effect for magnitude of SI and for complex-valued SI for vertical stimuli. Overall, we thus interpret our findings as additional support for a decline in featureselective attention in healthy old age, which does not seem to be accompanied by age differences in bottom-up stimulus processing.

\section{References}

Allen HA, Hutchinson CV, Ledgeway T, Gayle P (2010) The role of contrast sensitivity in global motion processing deficits in the elderly. J Vis 10:15. CrossRef Medline

Andersen SK, Hillyard SA, Müller MM (2008) Attention facilitates multiple stimulus features in parallel in human visual cortex. Curr Biol 18:10061009. CrossRef Medline

Andersen SK, Müller MM, Hillyard SA (2009) Color-selective attention need not be mediated by spatial attention. J Vis 9(6):2 1-7. CrossRef

Andersen SK, Fuchs S, Müller MM (2011) Effects of feature-selective and spatial attention at different stages of visual processing. J Cogn Neurosci 23:238-246. CrossRef Medline

Andersen SK, Müller MM, Martinovic J (2012) Bottom-up biases in feature-selective attention. J Neurosci 32:16953-16958. CrossRef Medline

Bach M (1996) The freiburg visual acuity test-automatic measurement of visual acuity. Optom Vis Sci 73:49-53. CrossRef Medline

Buffalo EA, Fries P, Landman R, Liang H, Desimone R (2010) A backward progression of attentional effects in the ventral stream. Proc Natl Acad Sci U S A 107:361-365. CrossRef Medline

Busse L, Wade AR, Carandini M (2009) Representation of concurrent stimuli by population activity in visual cortex. Neuron 64:931-942. CrossRef Medline

Chan YM, Battista J, McKendrick AM (2012) Aging effects on collinear facilitation. J Vis 12:21. CrossRef Medline

Delorme A, Makeig S (2004) EEGLAB: An open source toolbox for analysis of single-trial EEG dynamics including independent component analysis. J Neurosci Methods 134:9-21. CrossRef Medline

Desimone R, Duncan J (1995) Neural mechanisms of selective visual attention. Annu Rev Neurosci 18:193-222. CrossRef Medline 
Di Russo F, Spinelli D, Morrone MC (2001) Automatic gain control contrast mechanisms are modulated by attention in humans: evidence from visual evoked potentials. Vision Res 41:2435-2447. CrossRef Medline

Folstein MF, Folstein SE, McHugh PR (1975) "Mini-mental state." A practical method for grading the cognitive state of patients for the clinician. J Psychiatr Res 12:189-198. CrossRef Medline

Govenlock SW, Taylor CP, Sekuler AB, Bennett PJ (2009) The effect of aging on the orientational selectivity of the human visual system. Vision Res 49:164-172. CrossRef Medline

Gratton G, Coles MG, Donchin E (1983) A new method for off-line removal of ocular artifact. Electroencephalogr Clin Neurophysiol 55:468-484. CrossRef Medline

Hasher L, Zacks R (1988) Working memory, comprehension, and aging: a review and a new view. In: Psychology of learning and motivation, Vol 22 (Bower GH, ed), pp 193-225. New York: Academic.

Hubel DH, Wiesel TN (1962) Receptive fields, binocular interaction and functional architecture in the cat's visual cortex. J Physiol 160:106-154. Medline

Junghöfer M, Elbert T, Tucker DM, Rockstroh B (2000) Statistical control of artifacts in dense array EEG/MEG studies. Psychophysiology 37:523532. CrossRef Medline

Keitel C, Andersen SK, Quigley C, Müller MM (2013) Independent effects of attentional gain control and competitive interactions on visual stimulus processing. Cereb Cortex 23:940-946. CrossRef Medline

Lakatos P, Karmos G, Mehta AD, Ulbert I, Schroeder CE (2008) Entrainment of neuronal oscillations as a mechanism of attentional selection. Science 320:110-113. CrossRef Medline

Liu T, Larsson J, Carrasco M (2007) Feature-based attention modulates orientation-selective responses in human visual cortex. Neuron 55: 313323. CrossRef Medline

Lustig C, Hasher L, Zacks RT (2007) Inhibitory deficit theory: recent developments in a "new view." In: The place of inhibition in cognition (Gorfein DS, MacLeod CM, eds), pp 145-162. Washington, DC: American Psychological Association.

Maunsell JH, Cook EP (2002) The role of attention in visual processing. Philos Trans R Soc Lond B Biol Sci 357:1063-1072. CrossRef Medline
Müller MM, Andersen S, Trujillo NJ, Valdés-Sosa P, Malinowski P, Hillyard SA (2006) Feature-selective attention enhances color signals in early visual areas of the human brain. Proc Natl Acad Sci U S A 103:1425014254. CrossRef Medline

Owsley C (2011) Aging and vision. Vision Res 51:1610-1622. CrossRef Medline

Pilly PK, Seitz AR (2009) What a difference a parameter makes: a psychophysical comparison of random dot motion algorithms. Vision Res 49: 1599-1612. CrossRef Medline

Quigley C, Andersen SK, Müller MM (2012) Keeping focused: sustained spatial selective visual attention is maintained in healthy old age. Brain Res 1469:24-34. CrossRef Medline

Quigley C, Andersen SK, Schulze L, Grunwald M, Müller MM (2010) Feature-selective attention: evidence for a decline in old age. Neurosci Lett 474:5-8. CrossRef Medline

Schmitz TW, Cheng FH, De Rosa E (2010) Failing to ignore: paradoxical neural effects of perceptual load on early attentional selection in normal aging. J Neurosci 30:14750-14758. CrossRef Medline

Schmolesky MT, Wang Y, Pu M, Leventhal AG (2000) Degradation of stimulus selectivity of visual cortical cells in senescent rhesus monkeys. Nat Neurosci 3:384-390. CrossRef Medline

Snowden RJ, Kavanagh E (2006) Motion perception in the ageing visual system: minimum motion, motion coherence, and speed discrimination thresholds. Perception 35:9-24. CrossRef Medline

Talsma D, Kok A, Ridderinkhof KR (2006) Selective attention to spatial and non-spatial visual stimuli is affected differentially by age: effects on eventrelated brain potentials and performance data. Int J Psychophysiol 62: 249-261. Medline

Victor JD, Mast J (1991) A new statistic for steady-state evoked potentials. Electroencephalogr Clin Neurophysiol 78:378-388. CrossRef Medline

Yordanova J, Kolev V, Hohnsbein J, Falkenstein M (2004) Sensorimotor slowing with ageing is mediated by a functional dysregulation of motorgeneration processes: evidence from high-resolution event-related potentials. Brain 127:351-362. CrossRef Medline 